\title{
Evaluating the Capability of Information Technology to Prevent Adverse Drug Events: A Computer Simulation Approach
}

James G. Anderson, PhD, Stephen J. Jay, MD, Marilyn Anderson, BA, Thaddeus J. Hunt, BA

A b S t r a C t Background: The annual cost of morbidity and mortality due to medication errors in the U.S. has been estimated at $\$ 76.6$ billion. Information technology implemented systematically has the potential to significantly reduce medication errors that result in adverse drug events (ADEs).

Objective: To develop a computer simulation model that can be used to evaluate the effectiveness of information technology applications designed to detect and prevent medication errors that result in adverse drug effects.

Methods: A computer simulation model was constructed representing the medication delivery system in a hospital. STELLA, a continuous simulation software package, was used to construct the model. Parameters of the model were estimated from a study of prescription errors on two hospital medical/surgical units and used in the baseline simulation. Five prevention strategies were simulated based on information obtained from the literature.

Results: The model simulates the four stages of the medication delivery system: prescribing, transcribing, dispensing, and administering drugs. We simulated interventions that have been demonstrated in prior studies to decrease error rates. The results suggest that an integrated medication delivery system can save up to 1,226 days of excess hospitalization and \$1.4 million in associated costs annually in a large hospital. The results of the analyses regarding the effects of the interventions on the additional hospital costs associated with ADEs are somewhat sensitive to the distribution of errors in the hospital, more sensitive to the costs of an $\mathrm{ADE}$, and most sensitive to the proportion of medication errors resulting in ADEs.

Conclusions: The results suggest that clinical information systems are potentially a cost-effective means of preventing ADEs in hospitals and demonstrate the importance of viewing medication errors from a systems perspective. Prevention efforts that focus on a single stage of the process had limited impact on the overall error rate. This study suggests that system-wide changes to the medication delivery system are required to drastically reduce mediation errors that may result in ADEs in a hospital setting.

- J Am Med Inform Assoc. 2002;9:479-490. DOI 10.1197/jamia.M1099.

Affiliations of the authors: Purdue University, West Lafayette, IN (JGA); Indiana University School of Medicine, Indianapolis, IN (SJJ); Anderson Consulting, West Lafayette, IN (MA); Robert B. Katz and Associates, Chicago, IL (TJH).

Correspondence and reprints: James G. Anderson, PhD, Professor of Medical Sociology, Coordinator Rural Center for AIDS/STD
Prevention, Department of Sociology and Anthropology, 1365 Stone Hall, Purdue University, West Lafayette, IN 47907; e-mail: <andersonj@sri.soc.purdue.edu>.

Received for publication: 2/15/02; accepted for publication: $7 / 23 / 02$ 
Based on the Harvard Medical Practice study of 51 hospitals in the state of New York ${ }^{1,2}$ and a sample of hospitals in Utah and Colorado, ${ }^{3}$ the Institute of Medicine (IOM) estimated that between 44,000 and 98,000 deaths occur in the U.S. each year as a result of medical errors. ${ }^{4}$ Although the exact number of deaths due to medical errors is a subject of debate, ${ }^{5,6}$ metaanalyses of 39 prospective studies performed in the U.S. between 1966 and 1996 indicated that even when drugs are properly prescribed and administered, adverse drug reactions may rank between the fourth and seventh leading cause of deaths in the U.S., exceeding car accidents, suicide, homicide, or AIDS.?

The Harvard Medical Practice study found that the top cause of adverse events in hospitalized patients was drug complications, which accounted for 19 percent of the adverse events. ${ }^{2}$ An ADE is defined as "an injury resulting from medical intervention related to a drug." ${ }^{8}$ A recent study found that the rate of ADEs was 6.5 per 100 hospital admissions. Errors were detected at every stage of the process: ordering $(56 \%)$, transcription $(6 \%)$, dispensing $(4 \%)$, and administration (34\%). 8,9 The severity of the adverse drug events was $1 \%$ fatal, $12 \%$ life-threatening, 30\% serious, and 57\% significant. Other studies of hospitals in Utah and Colorado, ${ }^{3}$ pediatric inpatients, ${ }^{10}$ and hospital intensive care units, ${ }^{11}$ have also found high rates of ADEs.

Deaths due to medication errors in the U.S. may be increasing. One study found a 2.57 -fold increase in deaths attributed to medication errors between 1983 and 1993.12 One factor that may account for this increase is the shift from inpatient to outpatient care. ${ }^{13}$ During this decade, inpatient days fell by 21 percent while outpatient visits increased by $75 \%$.

Studies of hospitalized patients indicate that serious adverse drug events increase the length of hospital stay and costs. One study estimated the additional length of stay associated with an ADE was 2.2 days; the increase in cost associated with an ADE was $\$ 3,244 .{ }^{14}$ Based on these costs and incidence rates of ADEs, it was estimated that the annual costs attributed to all ADEs for a 700-bed hospital were $\$ 5.6$ million. A second study conducted at LDS Hospital in Salt Lake City estimated that the extra length of hospital stay attributable to an ADE was 1.74 days, whereas the extra cost of hospitalization was estimated to be $\$ 2,013$ per patient. ${ }^{15}$ During one year of the study a total of 567 ADEs were detected. The direct hospital costs associated with these ADEs were $\$ 1.1$ million. Over the four years of the study excess hospital costs due to ADEs were estimated at $\$ 4.5$ million. The total annual cost of morbidity and mortality due to drug-related errors in the U.S. has been estimated at $\$ 76.6$ billion. $^{16}$

Most hospitals rely on voluntary reporting which may result in the detection and reporting of only $5-10 \%$ of ADEs. ${ }^{17-20}$ At the same time, the increasing availability of computerized information systems in hospitals makes it possible to develop and implement automated surveillance systems to detect ADEs. ${ }^{21-23}$ Moreover, computerized physician order entry systems reduce medication errors and may reduce adverse drug event rates. ${ }^{24-29}$

In health care settings efforts to reduce errors traditionally have focused on training rules and sanctions. In contrast, a human factors approach advocates changing the system to reduce the likelihood that an error will occur and to permit the detection and intervention before the error causes harm to a patient. ${ }^{9,30}$ From this perspective errors can be viewed as a measure of the quality of the medication delivery system. As such, error rates are a measure of the rate of the system's failures. ${ }^{31}$

Two studies of medication errors have used a systems approach. In a study of two hospitals in Boston, medical errors that resulted in adverse drug events or potential ADEs were classified according to proximal cause and underlying system failures. ${ }^{9}$ Sixteen causes of system failures were identified, including lack of knowledge of the drug or the patient; transcription errors; faulty drug identification and dose checking; failure to check for allergies; and failure to track medication orders. Half of the 16 types of system failures could have been prevented by providing better, timelier information.

More recently, the Institute for Safe Medication Practices sponsored a nation-wide test of hospital pharmacy systems to identify and prevent serious drug-related errors. ${ }^{32}$ During the test, actual prescriptions that had caused serious injury or death to patients were entered into the system. Only a small percentage of errors were detected by the existing hospital pharmacy systems. Some of the system problems identified included lack of integration between the physician order entry and pharmacy systems, lack of integration between the laboratory and medication order systems, no clinical order screening capability, and complex order entry systems.

In the present study, we describe a computer simula- 
tion model that can be used to estimate the effectiveness of information system applications designed to detect and prevent medication errors that result in ADEs. The model was constructed using a systems approach that identifies components of the medication delivery system that make errors more likely to occur and more difficult to detect and prevent. It predicts the number of errors at each step in the medication delivery system, the number of associated ADEs, the extra number of days of hospitalization, and the excess costs of hospitalization attributable to ADEs.

Simulation was used because the medication delivery system in a hospital is complex and difficult to investigate in its entirety with more traditional methods. By building a computer model representing the system, we can simulate the behavior of the system over time and the effects of changes in the system's structure without disrupting the actual practice setting. ${ }^{33}$ Several earlier studies have used simulation to study the causes of medical errors. One study used discrete event simulation to estimate transcription errors in order entry into a hospital information system. ${ }^{34}$ Another study used a simulation system based on information processing theory to study errors in chemotherapy administration. ${ }^{35-36}$

\section{Methods}

\section{Hospital Setting}

The study was performed in a large private teaching hospital. The hospital had implemented the TDS HC 4000 hospital information system. During hospitalization, all patient data were entered into the computer system, creating an electronic medical record. Nursing units were equipped with three to seven computer terminals linked to the HIS. Physicians, nurses, unit secretaries, and other authorized personnel entered and retrieved patient information using these terminals.

At the time of this study, $91 \%$ of medication orders were written by physicians. All written orders were transcribed and entered into the computerized hospital information system by hospital ward clerks. Physicians entered 9\% of their orders directly into the system; ward clerks entered $81 \%$ of orders; other clinical personnel, such as physician assistants, entered the remaining $10 \%$. Medication orders were printed out in a centralized pharmacy where the drugs were dispensed and transported to the wards for administration.

\section{Data Collection}

The quality assurance records for the previous 12 months in the central pharmacy were used to obtain initial data about the number of medication errors that were detected prior to this study by a voluntary reporting system. To collect baseline data about medication errors, a pharmacy committee designed a report form. A list of types of mediation errors was adapted from previous published studies. ${ }^{37-41}$ An experienced registered pharmacist was assigned fulltime to the project to supervise and assist with the data collection on two medial/surgical units. During the day and evening shift for a 12-week period, every medication order written by a physician and entered into the HIS by a unit secretary was verified. A total of 6,966 drug orders were reviewed. When an error was detected, the pharmacist completed a form that identified the prescribing physician, unit secretary and / or nurse involved with the order, the nature of the incident, and the action taken to correct the error. When necessary, the physician who wrote the order was contacted. Hospital pharmacists were also available for consultation on the units during the day and evening shifts. They recorded information about all consultations. No chart reviews were performed in this study, nor was it possible to study actual adverse drug events that occurred in the hospital.

\section{Analysis}

A classification scheme was developed to classify the types of medication errors and their severity. ${ }^{37-41}$ During the previous 12 month period, only 48 medication errors or one error per 1,000 drug orders were reported throughout the entire hospital under the voluntary reporting system. During the 12-week study period when all drug orders on the two hospital units were reviewed, pharmacists detected 227 errors. This represented a rate of 32 errors per 1,000 orders. Rates of medication errors for the two hospital units are shown in Table 1.

On Four North, $85 \%$ of the errors were made in transcribing the physicians' orders and entering them into the medical information system. Physicians made errors in writing prescriptions in $13 \%$ of cases. The other $2 \%$ of errors were made in administering medications.

On the second Unit, Four South, $81 \%$ of the errors involved transcription of drug orders by ward clerks. Physicians' prescription errors amounted to $15 \%$, whereas errors in dispensing and administering medications each amounted to $2 \%$ of the total errors. 
Table 1

Types of Errors Detected on Two Hospital Units

\begin{tabular}{lcc} 
Type of Error & Four North $(\%)$ & Four South $(\%)$ \\
\hline Prescription & 13 & 15 \\
Transcription & 85 & 81 \\
Dispensation & 0 & 2 \\
Administration & 2 & 2 \\
Total & 100 & 100 \\
\hline
\end{tabular}

Medication errors were classified by their potential severity (Table 2). On both hospital units, over $70 \%$ of the errors were classified as problem orders. Orders were classified as problems if they involved duplicate therapy without the potential for adverse effects on the patient; lacked specific dose, dosage strength, route, or frequency information that would not have harmed the patient; or an incorrect order was written that was unlikely to be carried out.

Eighteen percent of the errors on both units were potentially significant. Potentially significant errors involved orders that specified a high dose of 1.4-4 times the normal dose of a medication that had the potential for an adverse effect; the dose was inadequate to produce the intended therapeutic effects; an illegible order, wrong medication or wrong route was specified that may have resulted in adverse effects or inadequate therapy.

Six percent of the medication errors were potentially serious. These errors might have resulted in serious toxic reactions or inadequate therapy for a serious illness. Medication errors classified as potentially serious included a high dose of a medication 4-10 times the normal dose that potentially would have resulted in a serious toxic reaction; a dose ordered for a drug used for a serious illness that was too low for a patient; the wrong medication was ordered with the potential for a serious toxic reaction; an illegible order or duplicate order with the potential for a serious toxic reaction.

The last category of medication errors was potentially fatal and might have resulted in the death of the patient. On Four South, 4\% of the errors were classified into this category. Potentially fatal errors included an order for a medication with a low therapeutic index that was greater than ten times the normal dose; a dose of a medication that would potentially result in pharmacologic effects or serum concentrations associated with fatal toxic reactions; a
Table 2

Severity of Medication Errors Detected on Two Medical/Surgical Hospital Units

\begin{tabular}{lcc}
\hline Severity & Four North $(\%)$ & Four South $(\%)$ \\
\hline Problem & 76 & 72 \\
Significant & 18 & 18 \\
Potentially Serious & 6 & 6 \\
Potentially Fatal & 0 & 4 \\
Total & 100 & 100 \\
\hline
\end{tabular}

drug that had the potential to produce a life-threatening reaction in the patient; and a dose of a lifesaving drug that was too low for the patient.

The coding of the types of errors and their severity was verified by a second registered pharmacist to ensure reliability. Also, similar results obtained on two separate medical/surgical units provide additional evidence of the reliability of the estimates of error rates used in this study.

\section{The Computer Simulation Model}

\section{Simulation}

A dynamic computer simulation model was constructed to model hospital medication errors using STELLA, a graphically-based, continuous simulation software package. ${ }^{42,43}$ Continuous simulation models are used when the system under investigation consists of a continuous flow of information, material, resources, or individuals and the system is dynamic, changing over time. ${ }^{33}$ The system under investigation is characterized in terms of state variables and control variables. State variables indicate the status of important characteristics of the system at each point in time. Examples of these variables include people, other resources, and information, such as the cumulative number of medication orders that have been written on a hospital unit at any time during the simulation. Control variables are rates of change and update the value of state variables in each time period. An example of a control variable is the number of new medications orders written per time period.

Components of the system are dynamic, may interact with each other, and may involve positive and negative feedback processes. The current model assumes that error rates at the prescription and transcription stage change nonlinearly over the period of time modeled as more physicians adopt interventions one and two. When relationships are nonlinear, the 


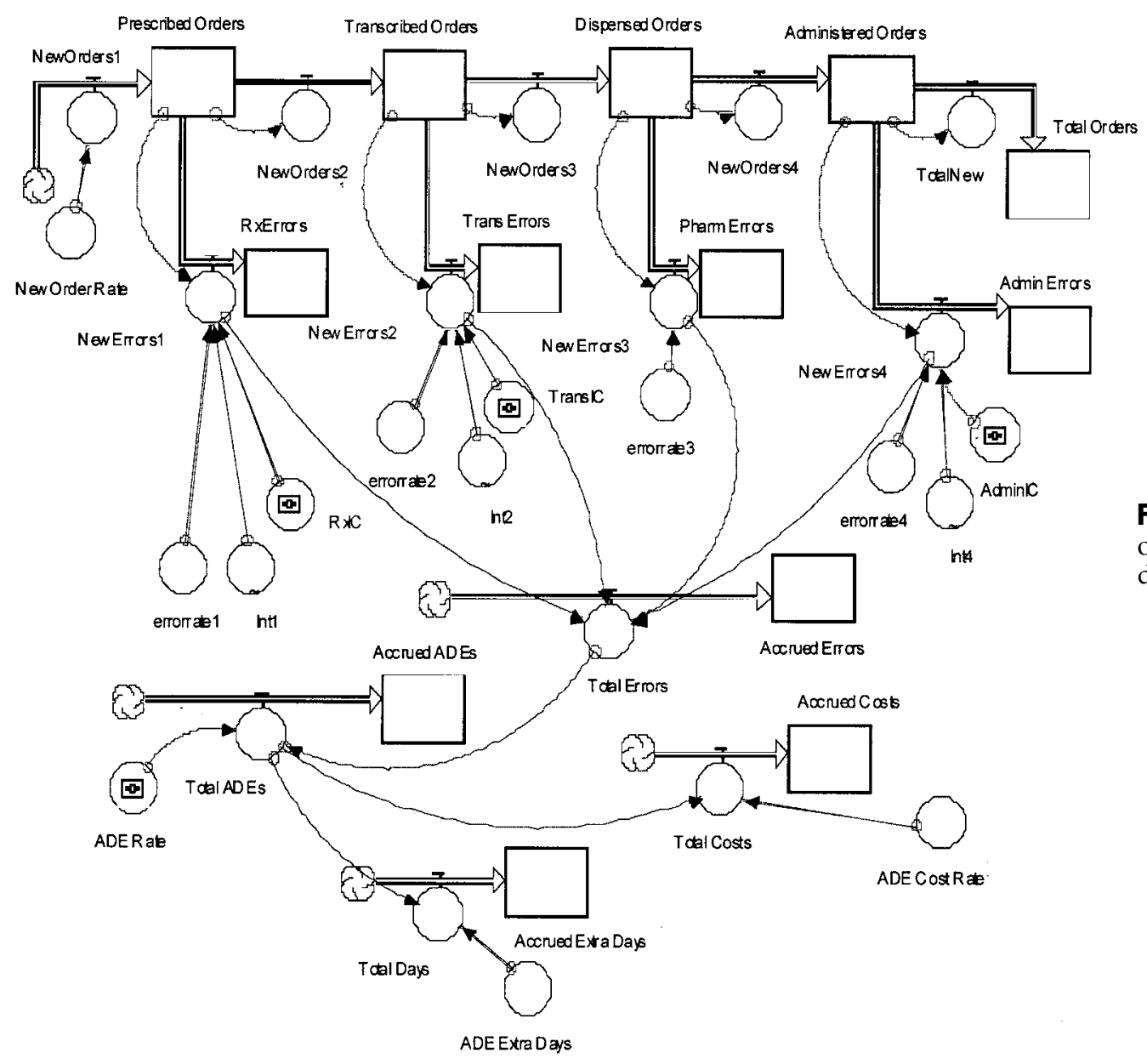

Figure 1 Systems model of a hospital medication delivery system.

system may exhibit complex, dynamic behavior over time. The mathematical model that underlies the simulation usually consists of a set of differential or finite difference equations. Numerical solutions of the equations that make up the model allow investigators to construct and test models that cannot be solved analytically.

The model, shown in Figure 1, assumes that medication orders are written or directly entered into the hospital information system by physicians. Written orders are transcribed by ward clerks on the medicalsurgical units. Once entered medication orders are transmitted directly to a central pharmacy where they are printed. After a check by a pharmacist, medications are dispensed and transported to the nursing unit. Registered nurses administer the medications to the patient.

The simulation begins by generating 4,060 medication orders, the average number of medication orders written by physicians each week on 14 hospital med$\mathrm{ical} /$ surgical units. Based on the analysis of medica- tion orders on the two hospital units, it was assumed that error rates at each stage of the process were variable and distributed normally. Means and standard deviations for error rates are shown in Table 3.

For example, at the prescription stage the error rate applied to the new medication orders is generated randomly from a normal distribution with a mean error rate of 4.6 errors per 1,000 medication orders and a standard deviation of 2.0. Orders without prescription errors move to the transcription stage, where a random error rate based on a mean of 27.0 transcription errors per 1,000 orders and a standard deviation of 10 is applied to the orders. This process is repeated for the dispensing and administration stages. The model assumes that an error that occurs at one stage of the process (e.g., prescription) does not propagate through the system, causing compound errors or multiple errors on the same drug order.

The model assumes that on the average an ADE results in 2.2 additional days of hospitalization. The cost of the additional days of hospitalization was esti- 
Table 3

Error Rates per 1,000 Medication Orders

\begin{tabular}{lrr}
\hline Stage & Mean & SD \\
\hline Prescription & 4.6 & 2.0 \\
Transcription & 27.0 & 10.0 \\
Dispensing & 4.3 & 2.0 \\
Administration & 5.7 & 2.0 \\
\hline
\end{tabular}

mated to be $\$ 2,595$ on average. These estimates were based on the results of two published studies. ${ }^{14-15}$

Two estimates were made of the number of ADEs and associated excess days of hospitalization and associated costs. The higher estimate assumed that $26 \%$ of the medication errors that could have resulted in serious toxic reactions or inadequate treatment would have resulted in ADEs if not detected and corrected. The low estimate assumed that only the $8 \%$ of drug errors that were potentially serious or fatal if undetected would have resulted in ADEs.

The simulation was run for a 52 week period with these baseline parameter estimates. Next, five strategies designed to reduce medication errors and potential ADEs were simulated for the same period of time.

\section{Simulation of Prevention Strategies}

First, the actual medication delivery system in the hospital was simulated, using the error rates obtained from the pharmacy study. Next, four simulations were performed with hypothetical changes in the system designed to prevent medication errors. Error rates for these simulations were obtained from the literature. Finally, a fifth simulation was performed assuming changes were made at all four stages of the process in order to prevent medication errors from occurring.

\section{Intervention 1: \\ Provision of Information at the Prescribing Stage}

The first intervention involved computerized prescribing. Errors may occur at every stage of the medication process, but our study and others indicated that a significant number of errors are made during ordering. These errors are most likely to result in serious adverse drug events. Efforts to change physician decisionmaking regarding the prescription of drugs, such as dissemination of educational material, lectures, and drug detailing by clinical pharmacists and consultation, have had short-term success. ${ }^{44}$ Computerized prescribing systems are potentially more effective.
The first intervention simulated was the implementation of a computer-based system that provides dosing information about drugs at the time orders are written. Such a system decreases the likelihood that an error will occur by facilitating access to information at the time the physician orders medications. Based on the low physician use of the order entry feature of the HIS at this hospital, the model assumes that over the course of one year, $50 \%$ of the physicians will gradually adopt the system in ordering medications and that this would result in an overall $20 \%$ reduction in prescription errors. It was also assumed that error rates at the other stages of the process would remain the same as in the baseline simulation.

\section{Intervention 2: Physician Computer Order Entry}

The second intervention involved computerized physician order entry. Many hospitals in the U.S. utilize ward clerks, unit secretaries or nurses to enter physician orders into computer-based information systems. At the same time, direct physician order entry into the system can significantly reduce medication errors by reducing transcription errors due to the illegibility of written orders. ${ }^{45}$

This study found that ward clerks made over $80 \%$ of the errors in transcribing physicians' written orders. Anderson and others ${ }^{46}$ demonstrated that by encouraging physicians to develop personal order sets, the percentage of medical orders directly entered into the medical information system could be significantly increased in a teaching hospital. An earlier computer simulation estimated that elimination of the need for transcription of medical orders could reduce errors by as much as $40 \% .{ }^{34}$ One study at Brigham and Woman's Hospital found that if all medical orders were entered on-line by physicians, $58 \%$ of all adverse events would be identifiable and potentially avoidable. ${ }^{8}$

The second intervention involved the implementation of a physician order entry system that permitted physicians to enter their own orders directly into the hospital information system. Because it was assumed that by the end of the first year of implementation only $50 \%$ of the drug orders would be directly entered into the information system by physicians, it was assumed that the overall transcription error rate would be reduced by $30 \%$.

\section{Intervention 3: Pharmacy System}

The third intervention involved the implementation of a unit dosing system. Pharmacy medication systems such as unit dosing can reduce medication 
Table 4

Errors by Stage of the Medication Delivery System

\begin{tabular}{|c|c|c|c|c|c|c|}
\hline Run & Prescription & Transcription & Dispensation & Administration & Total Errors & Total Orders \\
\hline BL & 948 & 5,220 & 868 & 1,099 & 8,136 & 195,392 \\
\hline 1 & 747 & 5,063 & 853 & 1,050 & 7,714 & 195,286 \\
\hline 2 & 1,016 & 4,050 & 881 & 1,151 & 7,099 & 195,245 \\
\hline 3 & 924 & 5,352 & 247 & 998 & 7,523 & 195,324 \\
\hline 4 & 931 & 5,457 & 842 & 451 & 7,680 & 195,268 \\
\hline 5 & 747 & 4,055 & 836 & 354 & 5,993 & 195,196 \\
\hline
\end{tabular}

errors. These systems dispense most medications from the pharmacy in a single unit or unit-dose package that is ready to be administered to the patient. One study found that a unit dosing system reduced medication errors by over $80 \% .{ }^{47,48}$ Based on these studies the third intervention assumed that the implementation of a unit dosing system would reduce dispensing errors on average by $80 \%$. Other rates for prescribing, transcribing, and administering medications were assumed to remain at baseline levels.

\section{Intervention 4:}

\section{Automated Medication Dispensing Systems}

Bar-coding of medications can lead to a reduction in errors at the administration stage. This practice has the potential to eliminate most errors involving drug substitutions. It improves tracking of medications that are administered and when they are given. ${ }^{49}$ The fourth intervention involved the implementation of a bar coding system to prevent errors frequently made in administering medications on the hospital units. It was assumed that such a system, once implemented, could reduce administration errors on average by $60 \%$.

Intervention 5:

\section{Comprehensive Medication Delivery System}

Bates has outlined a comprehensive medication delivery system that would include many of the prevention strategies outlined. ${ }^{47,50}$ The system would involve the use of a computerized order-entry system that would provide patient and medication information to the physician when medications are being prescribed. Direct order entry into the information system would significantly reduce transcription errors. The information system would transmit medication errors directly to the pharmacy where additional checks would be performed. Medications, as far as possible, would be dispensed at a point-of-care distribution system. When nurses administered a medication, they would scan a bar code to document that the correct medication had been administered. The fifth intervention involved implementation of all four strategies to prevent errors at each stage of the hospital medication process. All four error rates were modified based on the assumptions described above.

\section{Results}

The model was used to simulate the medication delivery system on 14 medical-surgical units in a teaching hospital. Tables 4 and 5 and Figures 2-7 show the results of the baseline run and the five runs that simulate potential information system applications designed to prevent medication errors. The baseline simulation generated a total of 195,392 drug orders over a 52-week period. A little over $4 \%$ of these orders involved errors. Almost $64 \%$ of these errors were made in the transcription stage. The model estimated that medication errors, if undetected, would result in 1,400-2,115 adverse drug events, a rate that ranges from 3.3 to 10.8 ADEs per 1,000 medication orders. The resulting additional days of hospitalization were estimated to cost between $\$ 1.6$ and $\$ 5.5$ million per year.

A sensitivity analysis was performed on the baseline parameters. Prescription error rates were varied by

\section{Table 5}

Rates of Medication Errors and ADEs per 1,000 Orders by Intervention

\begin{tabular}{cccc}
\hline Run & $\begin{array}{c}\text { Medication } \\
\text { Errors }\end{array}$ & $\begin{array}{c}\text { ADEs } \\
\text { Low Estimate }\end{array}$ & $\begin{array}{c}\text { ADEs } \\
\text { High Estimate }\end{array}$ \\
\hline BL & 41.6 & 3.3 & 10.8 \\
1 & 39.5 & 3.4 & 10.3 \\
2 & 38.3 & 2.8 & 9.4 \\
3 & 38.5 & 3.2 & 10.0 \\
4 & 39.3 & 2.9 & 10.2 \\
5 & 30.7 & 2.4 & 7.9 \\
\hline
\end{tabular}




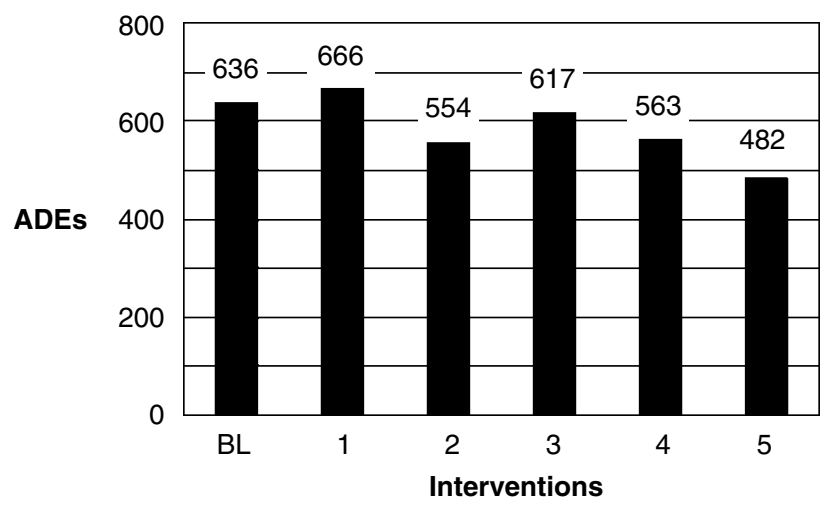

F i g u r e 2 Estimated ADEs by intervention low estimate.

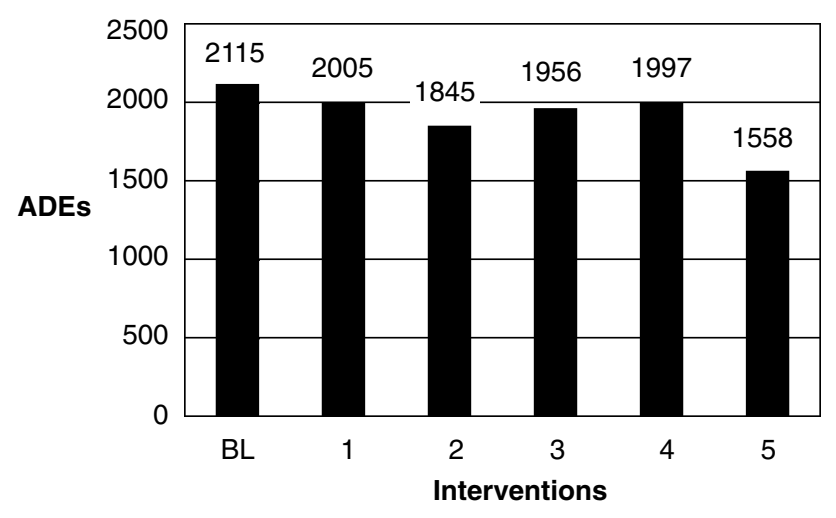

F i g u r e 3 Estimated ADEs by intervention high estimate.

$\pm 20 \%$ with little effect on the outcomes of the simulation. Changes in the estimates of the total cost of the additional days of hospitalization that resulted from ADEs ranged from $2 \%$ to $5 \%$. The model is more sensitive to the estimate of the average cost of the additional days of hospitalization due to ADEs. Using the cost estimate from the LDS hospital study, the model estimated that the annual cost of ADEs would be about $\$ 4.3$ million, which is similar to the estimate of $\$ 4$ million in our study. When the higher cost estimate from the Harvard study was used, annual costs were estimated to be $\$ 6.8$ million. Finally the model estimates are most sensitive to the assumption concerning what percentage of errors that result in ADEs. Two percentages were used in this study, $8 \%$ and $26 \%$.

The first intervention simulated was the implementation of a clinical information system that provides dosing information, parameters about drugs at the time orders are written, and warnings about excessive doses and drug-drug interactions. Such a system decreases the likelihood that an error will occur by facilitating access to information at the time that the physician orders drugs.

This intervention by itself failed to significantly reduce the overall error rate and ADE rate. While this intervention resulted in about a $21 \%$ reduction in prescription errors, total errors were only reduced by about $5 \%$. The model predicts that as many as 2,000 ADEs may occur resulting in 4,412 excess days of hospitalization costing over $\$ 5.2$ million annually.

The second intervention involved implementation of a physician order entry system. The simulation estimates that this strategy could reduce medication errors to 38.3 and ADEs to about 9.4 per 1,000 medication orders. However, the total number of errors was reduced by only about $4 \%$. Overall excess days of hospitalization could be reduced by as much as 600 days and the associated costs by as much as $\$ 213,000$ to $\$ 700,000$ annually.

The third intervention simulated involved the implementation of a unit dosing system in the central hos-

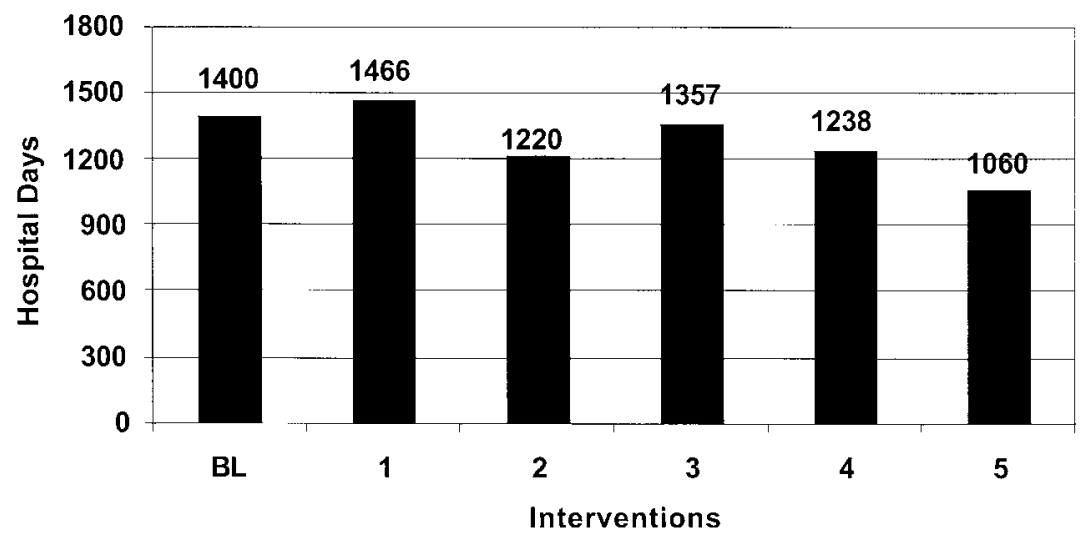

Figure 4 Estimated additional days of hospitalization by intervention: Low estimate. 
F i g u r 5 Estimated additional days of hospitalization by intervention: High estimate.
Figure $\mathbf{6}$ Estimated additional hospital costs by intervention: Low estimate.
F i g u re 7 Estimated additional hospital costs by intervention: High estimate.
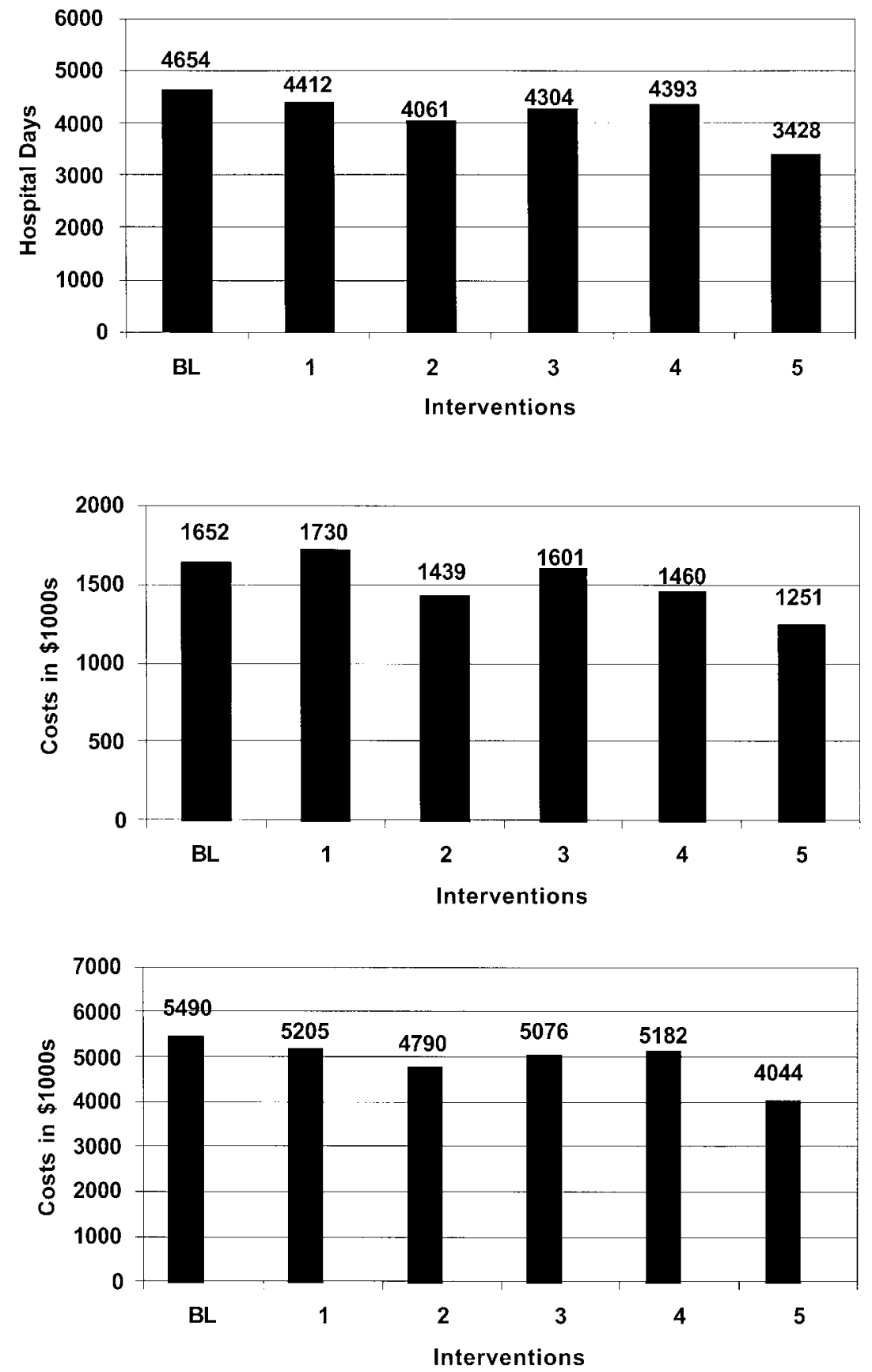

pital pharmacy. These systems reduce medication errors by dispensing medications in a single unit or unit-dose package that is ready for administration to the patient. The model predicts that the implementation of a unit-dose system would reduce medication errors at the administration stage by only about $9 \%$. The overall affect on the error rate and ADE rate is small. The model estimates that at most this inter- vention would reduce excess hospital days by 350 and annual costs by $\$ 413,442$.

The fourth prevention strategy simulated involved bar-coding of medications. This intervention could reduce errors when medications are administered and provide more complete documentation of medications that are administered. The model estimates 
that this prevention strategy would reduce only slightly the overall medication error rate and associated ADEs. Days of hospitalization would be reduced by less than 300 and associated costs by about $\$ 300,000$ or less annually.

The final run simulates the effects of implementing the comprehensive medication delivery system proposed by Bates. ${ }^{47,50}$ The model estimates that errors would be reduced at all stages of the medication delivery system. Medication error rates and associated ADEs could be reduced by over $26 \%$. It is estimated that a comprehensive information system could detect and prevent over 2,000 medication errors a year. The final implementation of an information system would have a substantial effect reducing excess hospital days by 1,226 and saving the hospital \$1.4 million in related costs annually.

\section{Discussion}

This study estimated the effectiveness of several computerized information system applications designed to detect and prevent medication errors that result in ADEs. The cost-effectiveness of these systems needs to be documented since current voluntary reporting systems for ADEs detect only a fraction of such events. ${ }^{17-20}$ The voluntary reporting system in the hospital that we studied detected only 1 medication error per 1,000 drug orders. Our study revealed an error rate of 32 per 1,000 medication orders. It was estimated that over 8,000 medication errors occur on 14 medical-surgical units each year.

The study that we performed estimated the frequency and types of medication errors in a specific hospital. These rates were used in the model to estimate ADEs, additional days of hospitalization, and associated hospital costs. The distribution of types of errors found in this hospital differed from other published studies in part because of the method we used to detect medication errors and in part because of the use of minimally trained ward clerks to transcribe physicians' written orders.

Based on error rates from our study of medical/surgical units at the teaching hospital and published estimates of the effects of ADEs on length of stay and hospital costs, a computer simulation model was developed. The model estimated that, under the current system, ADEs annually result in from 1,400 to 4,654 days of extra hospitalization. From $\$ 1.6$ to $\$ 5.5$ million in annual excess hospital costs were estimated. The lower estimate of the effects of medica- tion errors assumes that only the $8 \%$ of errors that might have led to serious toxic reactions, inadequate treatment, or death of the patient would have resulted in ADEs. The higher estimate assumes that the additional $18 \%$ of medication errors that involved omitted drugs, duplicate orders, or incorrect information also could have led to ADEs.

The model indicates that the implementation of a comprehensive medication delivery system designed to detect and prevent ADEs could save up to 1,226 days of hospitalization and \$1.4 million in hospital costs annually, even if it only prevented $26 \%$ of medication errors. These savings reflect only direct hospital costs. They do not include the additional costs of outpatient care, disability, and malpractice awards associated with ADEs. A recent study used the outpatient costs of ADEs to a managed care provider to project that these costs nationwide may be as high as $\$ 76.6$ billion. ${ }^{16}$

This study has several limitations. It was undertaken in only one teaching hospital in the Midwest. Consequently, the results may not be entirely generalizable to other hospitals with different medication delivery systems and information systems. However, the model is general. Therefore, error rates, ADE rates, and cost estimates can be modified to fit other institutions.

Medication error rates were determined by a 12-week study on two medical/surgical units by clinical pharmacists. However, resources were not available to perform chart audits or to investigate the actual adverse drug events that occurred in the hospital during this period. Consequently, we assumed that medication errors classified as potentially serious or fatal, if not detected and corrected, would have resulted in ADEs.

Moreover, we were unable to determine the exact number of additional days of hospitalization that occurred due to ADEs or the actual cost of the additional length of stay to the hospital. Instead we relied on estimates from two major published studies. ${ }^{14,15}$ Despite these limitations, estimates of medication error rates, ADE rates, and estimated costs due to excess hospitalization are in line with those reported in other major studies.

The study assumed that serious medication errors would result in ADEs. In reality, some of these medication errors would have been corrected before the medication was administered to the patient. It was also assumed that errors at each stage had an equal chance of resulting in an ADE. This is probably not correct, but the exact proportions of errors at each stage that result 
in ADEs is not known. Also, the cost estimates in this study underestimate the true costs of ADEs. Only direct costs of hospitalization were estimated. Other costs include outpatient care, disability, legal fees and malpractice awards resulting from ADEs.

Errors occur at every stage of the medication delivery system. Many result from systems failures and are not detected by the typical hospital self-reporting system. Moreover, this study indicated that systemwide changes to the process are required to significantly reduce medication errors in a hospital setting. Preventive efforts that focus solely on a single stage of the process have limited impact on the overall error rate. Bates and others suggest that clinical information systems that support the medication delivery system should be carefully designed and evaluated to ensure that they identify and prevent medication errors that result in ADEs. ${ }^{50}$ Moreover, clinical information systems need to be combined with other prevention strategies to reduce ADEs even more. Our simulation estimated that even a systemwide implementation of information technology would reduce medication errors and associated ADEs by only about $26 \%$. Studies indicate that several other approaches could be used in addition to the ones that we investigated.

One approach would be to significantly improve incident reporting of medical errors. ${ }^{20}$ Health care providers need to be trained to recognize changes in a patient's medical condition that may indicate an ADE and encouraged to report them promptly. Also, health care institutions need to create an environment that encourages the reporting of medication errors and investigation of system features that contributed to the error. ${ }^{51}$ Another promising approach is to more fully incorporate clinical pharmacists into the provision of patient care. ${ }^{52}$ At one hospital the participation of pharmacists in patient rounds on ICU units reduced the rate of ADEs from 33.0 to 11.6 per 1,000 patient days, almost a two-thirds reduction. ${ }^{53}$ This study demonstrates the importance of viewing adverse drug events from a systems perspective.

We conclude that the traditional medical approach to medication error prevention that relies on individual detection and voluntary reporting is reactive and largely ineffectual. ${ }^{54}$ If hospitals are to reduce medication errors that lead to ADEs and associated unnecessary costs and days of hospitalization, they will have to recognize the multiplicity of reasons that errors occur at each stage of the medication delivery system. Computerized information systems are an important means of detecting errors in time to take corrective action to prevent ADEs. The results of this study suggest that information systems are potentially a cost-effective means of preventing ADEs in hospitals, especially when coupled with other proven prevention strategies.

The authors acknowledge the assistance of Munir Shah, M.D., Michael Hamang, RPh, and the pharmacists in the Department of Pharmacy Services at Methodist Hospital of Indiana for their assistance in collecting the data for this study.

\section{References}

1. Brennan TA, Leape LL, Laird NM, et al. Incidence of adverse events and negligence in hospitalized patients. N Engl J Med. 1991;324:370-6.

2. Leape LL, Brennan TA, Laird N, et al. The nature of adverse events in hospitalized patients: results of the Harvard medical practice study II. N Engl J Med. 1991;324:377-84.

3. Thomas EJ, Sudderth DM, Burstein HR, et al. Incidence and types of adverse events and negligent care in Utah and Colorado. Med Care. 2000; 28:261-71.

4. Kohn LT, Corrigan JM, Donaldson MS (eds). To Err is Human: Building a Safer Health System. Washington, DC, National Academy Press, 1999.

5. McDonald CJ, Weiner M, Hui SL. Deaths due to medical errors are exaggerated in Institute of Medicine report. JAMA. 2000;284:93-5.

6. Leape LL, Institute of Medicine medical error figures are not exaggerated [comment]. JAMA. 2000;284:95-7.

7. Lazarou J, Pomeranz BH, Corey PN. Incidence of adverse drug reactions in hospitalized patients: a meta-analysis of prospective studies. JAMA. 1998;279:1200-5.

8. Bates DW, Cullen DJ, Laird N et al. Incidence of adverse drug events and potential adverse drug events. JAMA. 1995; 274:29-34.

9. Leape LL, Bates DW, Cullen DJ et al. Systems analysis of adverse drug events. JAMA. 1995;274:35-43.

10. Koushal R, Bates DW, Landrigan $C$ et al. Medication errors and adverse drug events in pediatric inpatients. JAMA. 2001; 285:2114-20.

11. Cullen DJ, Sweitzer BJ, Bates DW, et al. Preventable adverse drug events in hospitalized patients: A comparative study of intensive care and general care units. Crit Care Med. 1997; 25:1289-97.

12. Phillips DP, Christenfeld N, Glynn LM. Increase in US medication-error deaths between 1983 and 1993. Lancet. 1998; 351:643-4.

13. Honigman B, Lee J, Rothschild J, et al. Using computerized data to identify adverse drug events in outpatients. J Am Med Inform Assoc. 2001;8:254-66.

14. Bates DW, Spell NS, Cullen DJ, et al. The costs of adverse drug events in hospitalized patients. JAMA. 1997;277:307-11.

15. Classen DC, Pestotnik SL, Evans RS, et al. Adverse drug events in hospitalized patients: Excess length of stay, extra costs, and attributable mortality. JAMA. 1997;277:301-6.

16. Johnson JA, Bootman JL. Drug-related morbidity and mortality: a cost of illness model. Arch Intern Med. 1995:155:1949-56.

17. Berry LL, Segal R, Sherrin TP, Fudge KA. Sensitivity and specificity of three methods of detecting adverse drug relations. Am J Hosp Pharm. 1988;45:1534-9. 
18. O'Neil AC, Petersen LA, Cook EF, et al. A comparison of physicians self-reporting with medical record reviews to identify medical adverse Events. Ann Intern Med. 1993;119:370-6.

19. Chrischilles EA, Seager ET, Wallace RB. Self-reported adverse drug reactions and related resource use. Ann Intern Med. 1992; 117:634-40.

20. Cullen DJ, Bates DW, Small SD, et al. The incident reporting system does not detect adverse drug events: A problem for quality improvement. Journal of Quality Improvement. 1995; 21:541-8.

21. Classen DC, Pestotnik SL, Evans RS, Burke JP. Computerized surveillance of adverse drug events in hospital patients. JAMA. 1991;266:2847-51.

22. Bates DW, O'Neil AC, Boyle D, et al. Potential identifiability and preventability of adverse events using information systems. JAMIA. 1994;1:404-11.

23. Jha AK, Kuperman GJ, Teich JM, et al. Identifying adverse drug effects: Development of a computer-based monitor and comparison with chart review and simulated voluntary report. J Am Med Inform Assoc. 1998;5:305-14.

24. Evans RS, Pestotnik SL, Classen DC, et al. Prevention of adverse drug events through computerized surveillance. Proc Annu Symp Comput Appl Med Care. 1993:161-5.

25. Evans RS, Pestotnik SL, Classen DC, et al. A computer-assisted management program for antibiotics and other antiinfective agents. N Engl J Med. 1998; 338:232-8.

26. Bates DW, Leape LL, Cullen DJ. Effect of computerized physician order entry and a team intervention on prevention of serious medication errors. JAMA. 1998;280:1311-6.

27. Bates DW, Teich JM, Lee J, et al. The impact of computerized physician order entry on medication error prevention. J Am Med Inform Assoc. 1999;6:313-21.

28. Raschke RA, Collihare B, Wundertlich TA, et al. A computer alert system to prevent injury from adverse drug events. JAMA 1998;280:15:1317-20.

29. Agency for Healthcare Research and Quality. Reducing and Preventing Adverse Drug Events to Decrease Hospital Costs. Research in Action, Issue 1. AHRQ Publication Number 01-0020, March 2001. Agency for Healthcare Research and quality, Rockville, MD, <http:/ / www.ahrq.gov/qual/aderia/aderia.htm>.

30. Moray N. Error reduction as a systems problem. In Bogner MS (ed): Human Errors in Medicine. Hillsdale, NJ, Erlbaum, 1994.

31. Barker KN, Allan EL. Research on drug-use-system errors. Am J Health-Syst Pharm. 1995; 52:400-3.

32. Institute for Safe Medication Practices. Over-reliance on computer systems may place patients at great risk. ISMP Medication Safety Alert, 1999. Huntingdon Valley, PA, ISMP, 1999.

33. Anderson JG. Evaluation in health informatics: Computer simulation. Computers in Biology and Medicine. 2002; 32:151-64.

34. Anderson JG, Jay SJ, Clevenger SJ, et al. Physician utilization of a hospital information system: A computer simulation model. Proceedings of the 12th Annual Symposium on Computer Applications in Medical Care. Washington DC,
Computer Society of the IEEE, 1988: 858-61.

35. Fridsma DB. Error analysis using organizational simulation. Proc AMIA Annu Fall Symp. 2000:260-4.

36. Fridsma DB. Modeling medical protocols for organizational simulations: An information-processing approach. Comput Math Organ Theory. 1998; 4:71-95.

37. Betz RP, Levy HB. An interdisciplinary method of classifying and monitoring medication errors. Am J Hosp Pharm, 1985;42:1724-32.

38. Blum KV, Abel SR, Urbanski CJ, Pierce JM. Medication error prevention by pharmacists. Am J Hosp Pharm, 1988;45:1902-3.

39. Davis NM, Cohen MR. Medication Errors: Causes and Prevention. Philadelphia, GF Stickley, 1981.

40. Lesar JS, Briceland LL, Delcoure K, et al. Medication prescribing errors in a teaching hospital. JAMA. 1990;263:2329-34.

41. Vincer MU. Drug errors and incidents in a neonatal intensive care unit. AJDS. 1989;143:737-40.

42. Hannon B, Ruth M. Dynamic Modeling. New York, SpringerVerlag, 1994

43. Anderson JG. Computer simulation in the health sciences: modeling dynamic systems. Proceedings of the Congress Nacional de Economia. Las Palmas de Gran Canaria, Spain, 1995, pp 123-40.

44. Soumerai SB, Avorn J. Efficacy an cost-containment in hospital pharmacotherapy: State of the art and future directions. Milbank MEM Fund Q Helath Soc. 1984; 62:447-74.

45. Sittig DF, Stead WW. Computer-based physician order entry: The state of the art. J Am Med Informat Assoc. 1994;1:108-23.

46. Anderson JG, Jay SJ, Perry J, Anderson MM. Modifying physician use of a hospital information system: A quasi-experimental study. In Anderson JG, Aydin CE, Jay SJ (eds): Evaluating Health Care Information Systems: Methods and Applications. Thousand Oaks, CA, Sage Publications, 1994, pp 276-87.

47. Bates DW. Medication errors: How common are they and what can be done to prevent them? Drug Safe. 1996;5:303-10.

48. Simborg DW, Derewicz HJ. A highly automated hospital medication system: Five years' experience and evaluation. Ann Intern Med. 1975;83:342-6.

49. Brient K. Bar-coding facilitates patient-focused care. Health Inform. 1995;12-38-42.

50. Bates DW, Cohen M, Leape LL, et al. Reducing the frequency of errors in medicine using information technology. J Am Med Inform Assoc. 2001;8:299-308.

51. Sexton JB, Thomas EJ, Helmreich RL. Error, stress and teamwork in medicine and aviation: Cross-sectional surveys. BMJ. 2000;320:745-9.

52. Folli HL, Poole RL, Benitz WE, Russo JC. Medication error prevention by clinical pharmacists in two children's hospitals. Pediatrics. 1987;79:718-22.

53. Leape LL, Cullen DJ, Clapp MD, et al. Pharmacist participation on physician rounds and adverse drug events in the intensive care unit. JAMA. 1999;282:267-70.

54. Leape LL. Error in Medicine. JAMA. 1994;272:1851-68. 